\title{
High-density lipoprotein in chronic renal failure and after renal transplantation
}

\author{
ELLIOTT SAVDIE, JOYCE C GIBSON, JOHN H STEWART, LEON A SIMONS
}

British Medical fournal, 1979, 1, 928-930

\section{Summary and conclusions}

Serum high-density-lipoprotein (HDL) cholesterol and apoprotein (apo) A concentrations were significantly reduced at the time of renal transplantation in 26 patients with chronic renal failure. In a prospective evaluation the behaviour of HDL concentrations after grafting was found to depend on renal function. Graft function was sustained in 19 patients, in whom HDL-cholesterol and apo $A$ concentrations increased to lie within normal limits by six months after the operation. Successful transplantation also restored to normal the lipid and protein content of HDL as expressed by the ratio of HDL cholesterol to apo $A$. When transplant function was not sustained (seven patients), however, no changes in HDL were observed up to the time of the graft loss.

Such changes in HDL with successful kidney grafting augur well in a population with many risk factors for coronary heart disease.

\section{Introduction}

Epidemiological studies linking low concentrations of highdensity-lipoprotein (HDL) cholesterol with an increased risk of coronary heart disease $\mathrm{e}^{1-3}$ have particular relevance to end-stage chronic renal failure. Patients who are treated by regular dialysis are at increased risk from coronary heart disease, ${ }^{4}$ and cardiovascular disease generally is the leading cause of death in this population. ${ }^{5}$ This high risk may continue after transplantation, ${ }^{6}$ at least for the first months. ${ }^{7}$ HDL is reduced in concentration and perhaps also altered in composition in chronic renal failure. Concentrations of both HDL cholesterol ${ }^{8-10}$ and total apoprotein (apo) A, ${ }^{11}$ the major protein of HDL, are decreased whether or not the renal failure is treated by regular haemodialysis. Concentrations of apo AI, however, the dominant constituent peptide of apo A, have been reported to be normal, ${ }^{10}$ which may indicate a change in the structure of HDL in uraemia.

There is disagreement regarding HDL concentrations after chronic renal failure has been reversed by kidney transplantation. One repor $\mathrm{t}^{12}$ showed an increase in $\alpha$-lipoprotein concentrations. In a later case-control study normal concentrations of apo A were found in long-term transplant recipients, ${ }^{11}$ but HDLcholesterol concentrations have been reported to be low, ${ }^{13}$ normal, ${ }^{8}$ and high. ${ }^{14}$ Because of this controversy and in view of

\footnotetext{
Department of Medical Research, Kanematsu Memorial Institute, Sydney Hospital, Sydney, New South Wales, Australia

ELLIOTT SAVDIE, MRCP, FRACP, research fellow JOHN H STEWART, FRCP, FRACP, renal physician

Departments of Medicine, St Vincent's Hospital and University of New South Wales, Sydney, New South Wales, Australia JOYCE C GIBSON, DSC, scientific officer

LEON A SIMONS, FRACP, MRCP, senior lecturer in medicine
}

the importance of a normal concentration and composition of HDL to a population with a high prevalence of hypertension and hyperlipidaemia ${ }^{6}$ we undertook a prospective evaluation of the changes in HDL after renal transplantation by measuring in parallel HDL-cholesterol and apo A concentrations.

\section{Patients and methods}

We studied 26 recipients of cadaveric kidney allografts who underwent grafting at Sydney Hospital between January and November 1977. They had been treated by maintenance haemodialysis for endstage renal failure, the causes of which were similar to those previously reported. ${ }^{15}$ Immunosuppressive treatment after grafting included short-term parenteral antilymphocyte globulin and actinomycin $C$ and long-term oral azathioprine and prednisone. ${ }^{16}$ Venous blood for the measurement of serum lipid concentrations was drawn into plain glass tubes after a 10-hour overnight fast. Patients were sampled immediately before transplantation and at regular intervals thereafter for up to 16 months or until the graft failed. The serum was either separated and stored at $4^{\circ} \mathrm{C}$ for assay within four weeks or frozen at $-20^{\circ} \mathrm{C}$ if assay was to be further delayed.

Total cholesterol concentrations were measured on whole serum using the CHOD-PAP enzymatic method ${ }^{17}$ (Boehringer Mannheim) and total triglyceride concentrations with the Technicon AutoAnalyzer after isopropanol extraction. HDL cholesterol was assayed enzymatically in the serum supernatant remaining after low- and very-lowdensity lipoproteins (LDL and VLDL) had been precipitated using dextran sulphate and magnesium chloride ${ }^{18}$ to final concentrations of $0.9 \%$ and $120 \mathrm{mmol} / 1$ respectively. Standards of crystalline cholesterol in isopropanol and of aqueous cholesterol were included in each assay batch, and accuracy was verified with reconstituted lyophilised human serum with a known cholesterol concentration (Precilip, Boehringer Mannheim). The precision of the HDLcholesterol assay, determined by quintuplicate analysis of three separate sera, was $2 \%$ within each run and $5 \%$ between runs (coefficients of variation). Total serum apo A concentrations were assayed in appropriate dilutions of whole serum by Rocket immunoelectrophoresis using rabbit antiserum to human $\alpha$-lipoprotein as described. ${ }^{11}$ The assay therefore measured the sum of apo AI and apo AII concentrations.

For comparison, the above assays were also performed on the fasting sera of 49 men and 52 women attending a multiphasic health screening clinic in Sydney. These 101 control subjects were chosen, independent of plasma lipid concentrations, from a larger group of 159 randomly selected subjects after exclusion of those who had organic symptoms, who were taking medications known to affect serum lipid concentrations, or who had laboratory profiles suggesting metabolic, renal, hepatic, or blood disease.

Data were analysed using standard parametric methods including Student's $t$ test for paired and unpaired data and linear regression analysis.

\section{Results}

The outcome was successful in 19 of the 26 patients studied (nine men, 10 women), with sustained and adequate graft function nine to 16 months after transplantation. In seven patients (six men, one woman) graft function ceased within four months (mean 1.7 months) after transplantation; one patient died, while the other six returned to dialysis treatment.

Men in whom the outcome was successful were similar to the controls in respect of age and relative body weight at transplantation (table I). Examination of the data obtained one, three, and six months after transplantation in these nine men disclosed that with the 
TABLE I-Clinical data and lipid concentrations at transplantation and after one, three, and six months in male and female patients in whom transplantation was successful and controls. Results given as means \pm 1 SD

\begin{tabular}{|c|c|c|c|c|c|c|c|c|c|c|}
\hline & \multicolumn{5}{|c|}{ Men } & \multicolumn{5}{|c|}{ Women } \\
\hline & \multicolumn{4}{|c|}{ Transplant recipients } & \multirow{2}{*}{ Controls } & \multicolumn{4}{|c|}{ Transplant recipients } & \multirow{2}{*}{ Controls } \\
\hline & $\begin{array}{l}\text { At trans- } \\
\text { plantation }\end{array}$ & 1 month & 3 months & 6 months & & $\begin{array}{l}\text { At trans- } \\
\text { plantation }\end{array}$ & 1 month & 3 months & 6 months & \\
\hline $\begin{array}{l}\text { No of subjects } \\
\text { Age (years) } \\
\text { Relative body weight }\left({ }^{\circ}\right) \\
\text { Urea (mmol/l) } \\
\text { Creatinine }(\mathrm{mmol} / \mathrm{l}) \\
\text { Prednisone dosage (mg/day) } \\
\text { HDL cholesterol (mmol/l) } \\
\text { Apoprotein A (g/l) } \\
\text { HDL cholesterol: apoprotein A }\end{array}$ & $\begin{array}{c}9 \\
39 \pm 10 \\
100 \pm 11 \\
25 \cdot 8 \pm 9 \cdot 4 \\
0 \cdot 95 \pm 0 \cdot 22 \\
0 \\
0 \cdot 70 \pm 0 \cdot 20^{* *} \\
1 \cdot 86 \pm 0 \cdot 39^{*}\end{array}$ & $\begin{aligned} & 9 \\
& 99 \pm 13 \\
& 26 \cdot 4 \pm 13 \cdot 3 \\
& 0 \cdot 41 \pm 0 \cdot 32 \\
& 76 \pm 32 \\
& 0 \cdot 78 \pm 0 \cdot 23 \\
& 1 \cdot 84 \pm 0 \cdot 41\end{aligned}$ & $\begin{array}{c}9 \\
97 \pm 10 \\
18 \cdot 6 \pm 16 \cdot 8 \\
0 \cdot 25 \pm 0 \cdot 21 \\
36 \pm 14 \\
0.94 \pm 0 \cdot 29 \dagger \\
1.99 \pm 0.33\end{array}$ & $\begin{array}{c}8 \\
100 \pm 8 \\
13 \cdot 1 \pm 6 \cdot 8 \\
0 \cdot 18 \pm 0 \cdot 02 \\
26 \pm 22 \\
1 \cdot 04 \pm 0 \cdot 39+\dagger \\
2 \cdot 16 \pm 0 \cdot 44 \dagger \dagger\end{array}$ & $\begin{array}{c}49 \\
45 \pm 13 \\
105 \pm 10 \\
0 \cdot 10 \pm 0 \cdot 01 \\
0 \\
1 \cdot 19 \pm 0 \cdot 29 \\
2 \cdot 20 \pm 0 \cdot 39\end{array}$ & $\begin{array}{c}10 \\
40 \pm 13 \\
98 \pm 20 \\
27 \cdot 1 \pm 11 \cdot 8 \\
0 \cdot 93 \pm 0 \cdot 30 \\
0 \\
0 \cdot 81 \pm 0 \cdot 18^{* *} \\
1 \cdot 98 \pm 0 \cdot 40^{* *}\end{array}$ & $\begin{array}{c}10 \\
96 \pm 20 \\
21 \cdot 9 \pm 12 \cdot 7 \\
0 \cdot 25 \pm 0 \cdot 15 \\
80 \pm 65 \\
1 \cdot 14 \pm 0 \cdot 36 \dagger \\
2 \cdot 11 \pm 0 \cdot 40\end{array}$ & $\begin{array}{c}8 \\
96 \pm 13 \\
12 \cdot 7 \pm 4 \cdot 4 \\
0 \cdot 14 \pm 0 \cdot 07 \\
78 \pm 106 \\
1 \cdot 12 \pm 0 \cdot 42 \\
2 \cdot 19 \pm 0 \cdot 49\end{array}$ & $\begin{array}{c}102 \pm 16 \\
9 \cdot 7 \pm 2 \cdot 4 \\
0 \cdot 12 \pm 0 \cdot 04 \\
18 \pm 6 \\
1 \cdot 30 \pm 0 \cdot 49 \dagger \dagger \\
2 \cdot 16 \pm 0.54\end{array}$ & $\begin{array}{c}52 \\
43 \pm 13 \\
104 \pm 16 \\
0.08 \pm 0 \cdot 01 \\
0 \\
1 \cdot 40 \pm 0.31 \\
2 \cdot 31 \pm 0.29\end{array}$ \\
\hline $\begin{array}{l}\text { w/w ratio } \\
\text { Total cholesterol (mmol/l) } \\
\text { HDL cholesterol : total }\end{array}$ & $\begin{array}{l}0 \cdot 15 \pm 0 \cdot 03^{* *} \\
5 \cdot 38 \pm 1.53\end{array}$ & $\begin{array}{l}0.16 \pm 0.03 \\
4 \cdot 68 \pm 0.99\end{array}$ & $\begin{array}{c}0 \cdot 18 \pm 0 \cdot 04 \\
5 \cdot 27 \pm 1 \cdot 06\end{array}$ & $\begin{array}{l}0 \cdot 18 \pm 0 \cdot 04 \dagger \\
6 \cdot 21 \pm 1 \cdot 35\end{array}$ & $\begin{array}{l}0 \cdot 21 \pm 0.04 \\
5.92 \pm 1.06\end{array}$ & $\begin{array}{l}0 \cdot 16 \pm 0.04^{* *} \\
5 \cdot 56 \pm 1.53\end{array}$ & $\begin{array}{l}0.21 \pm 0.04 \dagger \\
5 \cdot 48 \pm 0.94\end{array}$ & $\begin{array}{l}0 \cdot 20 \pm 0.05 \\
5 \cdot 77 \pm 0.88\end{array}$ & $\begin{array}{l}0.23 \pm 0.05 \dagger \dagger \\
6.70 \pm 1 \cdot 25\end{array}$ & $\begin{array}{l}0 \cdot 23 \pm 0 \cdot 04 \\
6 \cdot 26 \pm 1 \cdot 19\end{array}$ \\
\hline $\begin{array}{l}\text { cholesterol } \\
\text { Total triglyceride }(\mathrm{mmol} / \mathrm{l})\end{array}$ & $\begin{array}{l}0 \cdot 14 \pm 0.05^{* *} \\
2 \cdot 95 \pm 1 \cdot 45^{* *}\end{array}$ & $\begin{array}{l}0.17 \pm 0.03 \\
2 \cdot 45: 0.55\end{array}$ & $\begin{array}{l}0 \cdot 18 \pm 0 \cdot 05 \\
2 \cdot 20 \pm 0 \cdot 70\end{array}$ & $\begin{array}{l}0.17 \pm 0.06 \\
2.52 \pm 1 \cdot 19\end{array}$ & $\begin{array}{l}0.21 \pm 0.06 \\
1.31 \pm 0.67\end{array}$ & $\begin{array}{l}0 \cdot 15 \pm 0.05^{* *} \\
2 \cdot 72 \pm 0.93^{* *}\end{array}$ & $\begin{array}{l}0.21 \pm 0.06 \dagger \dagger \\
2.46 \pm 0.80\end{array}$ & $\begin{array}{l}0.19 \pm 0.06 \dagger \\
2 \cdot 51 \pm 1.06\end{array}$ & $\begin{array}{l}0 \cdot 19 \pm 0.05 \\
2 \cdot 10 \pm 0.92\end{array}$ & $\begin{array}{l}0.23 \pm 0.07 \\
1.03 \pm 0.51\end{array}$ \\
\hline
\end{tabular}

Significance of difference: $* \mathrm{P}<0.05 ; * * \mathrm{P}<0.01$ for values at transplantation compared with those in healthy controls (unpaired $t$ test). $\dagger \mathrm{P}<0.05 ; \dagger+\mathrm{P}<0.01$ for values after one, three, and six months compared with those at transplantation (paired test).

ml. Triglyceride: $1 \mathrm{mmol} / 1 \approx 88.0 \mathrm{mg} / 100 \mathrm{ml}$.

progressive improvement in renal function (as manifested by serum urea and creatinine concentrations) the HDL-cholesterol and apo A concentrations concomitantly increased. By six months each of these values was significantly higher than at transplantation and no longer significantly different from controls. The ratio of HDL cholesterol to apo $\mathrm{A}$, which was significantly lower than in controls at transplantation, likewise increased progressively with time. The low ratio of HDL to total cholesterol at transplantation rose, though not significantly. At six months values for HDL cholesterol and apo $\mathrm{A}$ in the eight men sampled showed no significant correlation with any of five clinical or biochemical indices-namely, relative body weight, serum urea and creatinine concentrations, daily prednisone dose, and cumulative prednisone dosage since transplant action.

TABLE II-Clinical data and lipid concentrations at transplantation, after two weeks and one month, and at graft loss in patients in whom transplantation was unsuccessful (six men, one woman). Results given as means $\pm 1 S D$

\begin{tabular}{|c|c|c|c|c|}
\hline & $\begin{array}{l}\text { At trans- } \\
\text { plantation }\end{array}$ & 2 weeks & 1 month & $\begin{array}{l}\text { At graft loss } \\
\text { (mean } 1 \cdot 7 \\
\text { months) }\end{array}$ \\
\hline $\begin{array}{l}\text { No of patients } \\
\text { Age (years) }\end{array}$ & $\stackrel{7}{44+6}$ & 7 & 6 & 7 \\
\hline $\begin{array}{l}\text { Relative body weight }(\%) \\
\text { Urea }(\mathrm{mmol} / \mathrm{l}) \\
\text { Creatinine }(\mathrm{mmol} / \mathrm{l}) \\
\text { Prednisone dosage }(\mathrm{mg} / \mathrm{day}) \\
\text { HDL cholesterol (mmol/l) } \\
\text { Apoprotein A }(\mathrm{g} / \mathrm{l}) \\
\text { HDL cholesterol: apoprotein }\end{array}$ & $\begin{array}{c}107 \pm 18 \\
24.9 \pm 8.9 \\
0.93 \pm 0.28 \\
0 \\
0.73 \pm 0.18 \\
1.96 \pm 0.50\end{array}$ & $\begin{array}{l}103 \pm 19 \\
39 \cdot 6 \pm 14 \cdot 4 \\
0 \cdot 79 \pm 0 \cdot 20 \\
135 \pm 82 \\
0 \cdot 60 \pm 0 \cdot 23 \\
1 \cdot 64 \pm 0 \cdot 33\end{array}$ & $\begin{array}{l}103 \pm 13 \\
27 \cdot 8 \pm 9 \cdot 6 \\
0 \cdot 71 \pm 0 \cdot 27 \\
118 \pm 106 \\
0 \cdot 73 \pm 0 \cdot 13 \\
1 \cdot 65 \pm 0 \cdot 31\end{array}$ & $\begin{array}{l}101 \pm 15 \\
32 \cdot 8 \pm 12 \cdot 4 \\
0 \cdot 77 \pm 0 \cdot 23 \\
123 \pm 173 \\
0 \cdot 60 \pm 0 \cdot 21 \\
1 \cdot 50 \pm 0 \cdot 22\end{array}$ \\
\hline $\begin{array}{l}\text { A w/w ratio } \\
\text { Total cholesterol (mmol/l) } \\
\text { HDL cholesterol: total }\end{array}$ & $\begin{array}{l}0.15 \pm 0.04 \\
5.84 \pm 1.32\end{array}$ & $\begin{array}{l}0.14 \pm 0.06 \\
4 \cdot 29 \pm 0.70\end{array}$ & $\begin{array}{l}0.17 \pm 0.04 \\
4.75 \pm 0.65\end{array}$ & $\begin{array}{l}0 \cdot 16 \pm 0 \cdot 06 \\
4 \cdot 55 \pm 0 \cdot 68\end{array}$ \\
\hline $\begin{array}{l}\text { cholesterol } \\
\text { Total triglyceride }(\mathrm{mmol} / \mathrm{l})\end{array}$ & $\begin{array}{l}0 \cdot 13 \pm 0 \cdot 04 \\
3 \cdot 62 \pm 2 \cdot 20\end{array}$ & $\begin{array}{l}0 \cdot 14 \pm 0.04 \\
2 \cdot 95 \pm 0.75\end{array}$ & $\begin{array}{l}0.15 \pm 0.03 \\
2.90 \pm 2.53\end{array}$ & $\begin{array}{l}0.14 \pm 0.07 \\
3 \cdot 11 \pm 1 \cdot 11\end{array}$ \\
\hline
\end{tabular}

No significant difference between any values at two weeks, one month, and graft loss and values at transplantation (paired $t$ test).

Conversion: SI to traditional units-Urea: $1 \mathrm{mmol} / 1 \approx 6 \mathrm{mg} / 100 \mathrm{ml}$. Creatinine: $\mathrm{mg} / 100 \mathrm{ml}$. Triglyceride: $1 \mathrm{mmol} / 1 \approx 88.0 \mathrm{mg} / 100 \mathrm{ml}$.

Women in whom the outcome was successful also showed reduced concentrations of HDL cholesterol and apo A at transplantation and a pattern of response after transplantation similar to that in the men (table I). The rise in HDL-cholesterol concentrations at one and six months and in the ratio of HDL cholesterol to apo A at six months were significant. Unlike in the men, however, the rise in apo A concentrations was not significant, while that in the ratio of HDL to total cholesterol was significant at one and three months. At six months there was a significant inverse correlation $(r=-0.69$, $P<0.05)$ between the apo $A$ and serum creatinine concentrations in the nine women studied. No other significant correlations between apo $\mathrm{A}$ or HDL cholesterol and any clinical or biochemical variable could be shown at that time.

In the seven patients in whom the outcome was unsuccessful the clinical features and lipid values measured at transplantation were similar to those in the patients whose grafts did not fail (table II).
HDL-cholesterol and apo A concentrations and the derived parameters, however, remained unchanged at two and four weeks after transplantation and also in the last sample taken before death or graft nephrectomy (mean of 1.7 months after grafting).

In the 101 healthy controls there was a highly significant positive correlation between HDL-cholesterol and apo A concentrations $(\mathrm{r}=0.68, \mathrm{P}<0.001)$, represented by the regression line in the figure.

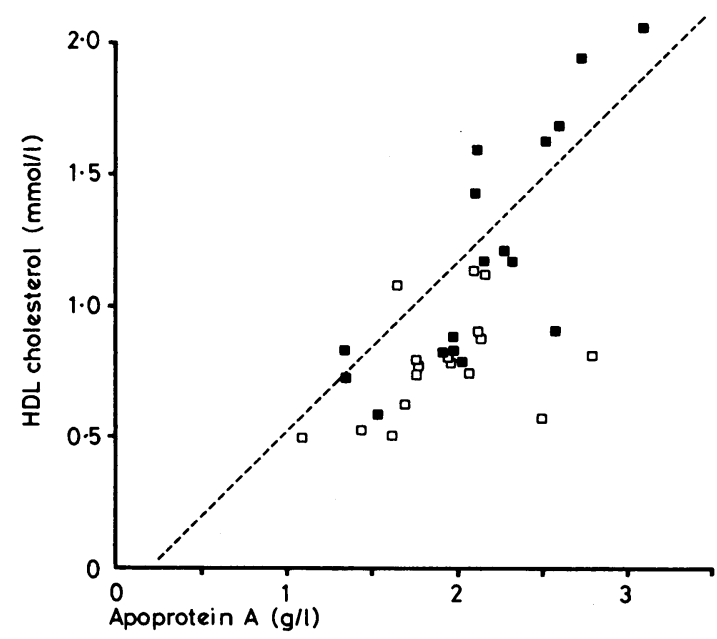

Relation between HDL-cholesterol and apoprotein A concentrations. $\square=$ Concentrations six months after grafting in 17 patients in whom transplantation was successful $(r=0.83) . \square=$ Concentrations in same 17 patients at transplantation $(r=0.43)$. Regression line obtained from values in 101 healthy controls $(r=0.68)$.

This relation was also studied at and six months after transplantation in the 17 men and women sampled at six months. At transplantation all but one of the points lay below and to the right of the regression line for the control population (indicating a relatively low ratio of lipid to protein) and there was no consistent relation between the two parameters $(r=0.43$, not significant). At six months the points lay more closely along the regression line and the relation was highly significant $(r=0.81, P<0.001)$.

\section{Discussion}

The principal finding of this study is that within six months successful renal transplantation reverses the abnormalities of HDL that occur in chronic renal failure. When renal function was restored HDL-cholesterol and apo A concentrations became 
normal, as did the composition of HDL as expressed by the ratio of HDL cholesterol to apo A. These data confirm the initial observation of a relation between $\alpha$-lipoprotein concentrations and the adequacy of kidney graft function. ${ }^{12}$ They also accord with results of previous case-control studies from our group reporting normal $\mathrm{HDL}$-cholesterol ${ }^{8}$ and apo $\mathrm{A}^{11}$ concentrations in long-term transplant recipients with stable graft function. Bagdade and Albers, however, reported low HDL-cholesterol concentrations in a group of long-term transplant recipients. ${ }^{13}$ This disagreement may be due in part to sampling variation as well as to the need to document HDL-cholesterol concentrations in men and women separately because of the higher concentrations normally found in women.

The mechanisms underlying reduced HDL concentrations in chronic renal failure have not been elucidated. Of possible importance is the associated increase in serum VLDL that is common in uraemia, resulting in hypertriglyceridaemia. HDLcholesterol concentrations are negatively correlated with fasting plasma triglyceride concentrations in both normal ${ }^{1-319}$ and hyperlipidaemic ${ }^{20}$ populations. This relation in turn reflects the inverse association between $\mathrm{HDL}_{2}$, the variable subspecies of HDL, and VLDL concentrations. ${ }^{21}$ Efficient exchange of apoproteins during the degradation of triglyceride-rich VLDL and chylomicrons may be an important step in determining HDL concentrations. ${ }^{20}$ In uraemia, triglyceride turnover ${ }^{22}{ }_{23}$ and clearance ${ }^{24}$ rates and lipoprotein lipase activities ${ }^{24}{ }^{25}$ are low, suggesting that this dynamic relation between VLDL and HDL may be affected.

In many patients in this series, particularly women, HDL concentrations after transplantation increased concomitantly with decreases in triglyceride concentrations. Return of the HDL concentrations to normal in both sexes, however, occurred in the absence of significant decreases in mean triglyceride concentrations, which were still high six months after transplantation. Thus hypertriglyceridaemia itself is probably only one factor in the reduced HDL concentrations in uraemia, an observation substantiated by the finding that patients receiving dialysis have lower HDL-cholesterol concentrations than controls even when the latter are matched for triglyceride concentrations. ${ }^{10}$

The close correlation between apo $\mathrm{A}$ and HDL-cholesterol concentrations observed in controls was absent in the samples obtained before transplantation but re-established at six months when graft function was satisfactory. Brunzell et al reported a similarly low correlation coefficient $(\mathbf{r}=0.34)$ between apo AI and $\mathrm{HDL}$ cholesterol in a population receiving dialysis. ${ }^{10}$ Uraemia reduces the binding to plasma proteins of metabolites, drugs and essential amino-acids, ${ }^{26}$ and hormones such as thyroxine. ${ }^{27}$ By a related mechanism uraemia may also interfere with the combination of cholesterol to its apoproteins.

High-dose prednisone treatment provides an alternative explanation for the improvement in HDL after transplantation, since the influence of cumulative prednisone dosage on total cholesterol and triglyceride concentrations in transplant recipients has been well documented, ${ }^{28}$ while a reduction in rates of triglyceride turnover has been observed when the prednisone is administered every second day rather than daily. ${ }^{29}$ For several reasons, however, we consider that prednisone was not responsible for the HDL changes reported here. Firstly, the patients in whom transplantation was unsuccessful showed no increment in HDL concentrations despite a mean daily dose of prednisone greater than that given to either of the successful groups. Secondly, six months after transplantation HDL concentrations could not be significantly correlated with daily or cumulative prednisone dosage in either sex. Thirdly, we did not observe increases in HDL concentrations during or after acute rejection episodes, despite steep increases in the prednisone dosage.

Finally, dietary factors and increased physical activity must also be considered. We did not assess their importance quantitatively but, of course, recipients who have had transplants for a long time consume less carbohydrate and more alcohol than their counterparts receiving dialysis ${ }^{8}$ dietary changes that both increase HDL concentration. ${ }^{30}{ }^{31}$ Increased physical activity, ${ }^{32}$ on the other hand, seems less likely to account for the changes in HDL, since the first six months after transplantation are characterised by prolonged periods of stay in hospital and variable steroid myopathy.

This study has important implications for the risk of coronary heart disease after transplantation. Restoring a normal concentration and composition of HDL may, on epidemiological grounds, offset any increased risk due to the rise in total serum cholesterol concentration. ${ }^{1}$ Although Ibels et al reported a persistently high mortality ${ }^{7}$ and morbidity ${ }^{6}$ from coronary heart disease in transplant recipients, a high proportion of those who sustained fatal myocardial infarcts after transplantation did so within three months ${ }^{7}$ and had had pre-existing ischaemic heart disease noted while receiving dialysis. ${ }^{33} \mathrm{Re}$-examination of our own data regarding 661 consecutive patients who underwent transplantation by the Sydney University group since 1967 indicates that 24 died from myocardial infarction, 11 within three months after grafting. In patients who survived the first year after transplantation the six-year cumulative probability of death from myocardial infarction was 0.054 . Although this rate is still higher than that in a random population, ${ }^{34}$ it may represent an improvement when compared with those patients who remain on long-term dialysis. ${ }^{4}$

This project was supported by the Australian Kidney Foundation. Requests for reprints should be addressed to ES.

\section{References}

${ }^{1}$ Gordon, T, et al, American fournal of Medicine, 1977, 62, 707.

${ }^{2}$ Miller, N E, et al, Lancet, 1977, 1, 965.

${ }^{3}$ Rhoads, G G, Gulbrandsen, C L, and Kagan, A, New England fournal of Medicine, 1976, 294, 293.

${ }^{4}$ Lindner, A, et al, New England fournal of Medicine, 1974, 290, 697.

5 Brunner, F P, et al, in Dialysis Transplantation Nephrology, p 3. Tunbridge Wells, Pitman Medical, 1976.

6 Ibels, L S, et al, Ouarterly fournal of Medicine, 1977, 46, 197.

${ }^{7}$ Ibels, L S, et al, British Medical fournal, 1974, 3, 552.

8 Ibels, L S, et al, Quarterly fournal of Medicine, 1975, 44 (NS), 601.

9 Bagdade, J, Casaretto, A, and Albers, J, Fournal of Laboratory and Clinical Medicine, 1976, 87, 37

10 Brunzell, J D, et al, Metabolism, 1977, 26, 903.

11 Gibson, J C, et al, Australian and New Zealand fournal of Medicine. In press.

12 Lewis, L A, et al, New England fournal of Medicine, 1966, 275, 1097.

13 Bagdade, J D, and Albers, J J, New England Fournal of Medicine, 1977, 296, 1436.

14 Abbott, L K, et al, Atherosclerosis, 1978, 30, 97.

15 Stewart, J H, et al, British Medical fournal, 1975, 1, 440

${ }_{16}$ Sheil, A G R, et al, Lancet, 1973, 2, 227.

17 Allain, C C, et al, Clinical Chemistry, 1974, 20, 470.

18 Kostner, G M, Clinical Chemistry, 1976, 22, 695.

19 Ewing, A M, Freeman, N K, and Lindgren, F T, Advances in Lipid Research, 1965, 3, 25.

20 Schaefer, E J, et al, Lancet, 1978, 2, 391.

21 Anderson, D W, Lancet, 1978, 1, 819.

22 Cattran, D C, et al, Annals of Internal Medicine, 1976, 85, 29.

${ }^{23}$ Savdie, E, et al, Australian and New Zealand fournal of Medicine, 1978, $8,240$.

${ }^{24}$ Ibels, L S, Reardon, M F, and Nestel, P J, Fournal of Laboratory and Clinical Medicine, 1976, 87, 648.

${ }^{25}$ Crawford, G A, Savdie, E, and Stewart, J H, Clinical Science and Molecular Medicine. In press.

${ }^{26}$ Farrell, P C, et al, Transactions of the American Society for Artificial Internal Organs, 1972, 18, 268.

27 Spaulding, S W, and Gregerman, R I, Fournal of Clinical Endocrinology and Metabolism, 1972, 34, 974.

28 Ibels, L S, et al, Transactions of the American Society for Artificial Internal Organs, 1975, 22, 46.

${ }^{29}$ Cattran, D C, et al, Kidney International, 1977, 11, 380.

30 Wilson, D E, and Lees, R S, fournal of Clinical Investigation, 1972, 51, 1051 .

${ }^{31}$ Belfrage, P, et al, European fournal of Clinical Investigation, 1977, 7, 127.

32 Lopez-S, A, et al, Atherosclerosis, 1974, $20,1$.

${ }_{33}$ Mahony, J F, et al, Fournal of the American Medical Association, 1976, 235, 2318 .

${ }^{34}$ Kannell, W B, et al, Annals of Internal Medicine, 1961, 55, 33.

(Accepted 7 February 1979) 